\title{
Preface
}

\section{Liquid Biopsy: A New Tool in Oncology}

\author{
José Luís Costa ${ }^{\mathrm{a}-\mathrm{c}}$ Fernando C. Schmitt ${ }^{\mathrm{a}-\mathrm{c}}$ \\ ai3S - Instituto de Investigação e Inovação em Saúde, Universidade do Porto, Porto, Portugal; \\ bIPATIMUP - Institute of Molecular Pathology and Immunology of the University of Porto, Porto, Portugal; \\ 'Faculty of Medicine, University of Porto, Porto, Portugal
}

The treatment of cancer has remarkably improved because of increased knowledge of the molecular abnormalities that drive human cancer growth. This has led to the development of ever more effective targeted cancer therapies. In light of these advances, the testing of molecular biomarkers for cancer patient stratification has become mandatory. Such tests are performed routinely using biopsy/cytology material from primary tumors obtained at the time of diagnosis. While this approach is suitable for diagnostic purposes, it precludes the follow-up of the patient during disease progression and eventual relapse.

The concept of liquid biopsy was introduced to oncology with the potential to revolutionize the management of cancer patients, eliminating the invasive procedures needed to obtain tissue samples and provide information on therapy response and disease relapse on the fly. Although liquid biopsy is already a reality in the management of cancer patients, there are some hurdles in the way before full deployment.

This special issue will focus on all aspects surrounding liquid biopsy, from technological developments to analyt- ical validation and clinical implementation. Poulet et al. [1] provide a general overview of the field, covering different aspects from the source of biological material to main technologies available for their study. Each aspect is further detailed in the following reviews. The concept of cfDNA and its application to the management of cancer patients is the focus of Fernandes Marques et al. [2], whereas the cellular component of liquid biopsies is reviewed by Abalde-Cela et al. [3], who conducted a search for studies published that provide details about their significance in the clinic. Additional sources of biological material (tumorderived exosomes, tumor-educated platelets, and circulating tumor RNAs) are focused on in the review by Junqueira-Neto et al. [4]. To finalize the issue, two reviews address the clinical applicability of liquid biopsies in the routine management of cancer patients. Pisapia et al. [5] critically review the available methodologies for ctDNA analysis in non-small cell lung cancer patients. Lastly, Clery et al. [6] add a note of caution to the field as not all types of acquired resistance to TKIs can be addressed by liquid biopsy. In these cases, cytopathology still plays a role.

\section{References}

1 Poulet G, Massias J, Taly V. Liquid biopsy: general concepts. Acta Cytol. 2019. DOI: https://doi.org/10.1159/000499337.

2 Fernandes Marques J, Pereira Reis J, Fernandes G, Hespanhol V, Machado JC, Costa JL. Circulating tumor DNA: a step into the future of cancer management. Acta Cytol. 2019. DOI: https://doi.org/10.1159/000492917.
3 Abalde-Cela S, Piairo P, Diéguez L. The significance of circulating tumour cells in the clinic. Acta Cytol. 2019. DOI: https://doi. org/10.1159/000495417.

4 Junqueira-Neto S, Batista IA, Costa JL, Melo SA. Liquid biopsy beyond circulating tumor cells and cell-free DNA. Acta Cytol. 2019. DOI: https://doi.org/10.1159/000493969.
5 Pisapia P, Malapelle U, Troncone G. Liquid biopsy and lung cancer. Acta Cytol. 2019. DOI: https://doi.org/10.1159/000492710.

6 Clery E, Pisapia P, Vigliar E, Malapelle U, Bellevicine C, Troncone G, et al. Role of cytomorphology in the era of liquid biopsy. Acta Cytol. 2019. DOI: https://doi.org/10.1159/ 000499338.

\section{KARGER}

(c) 2019 S. Karger AG, Basel

E-Mail karger@karger.com

www.karger.com/acy
Prof. Fernando C. Schmitt

IPATIMUP - Institute of Molecular Pathology and Immunology of

the University of Porto, Rua Júlio Amaral de Carvalho, 45

PT-4200-135 Porto (Portugal)

E-Mail fernando.schmitt@ipatimup.pt 